\title{
The relation between seismicity and water level changes in the Koyna-Warna region, India
}

\author{
J. Pavan Kumar ${ }^{1}$, D. V. Ramana ${ }^{1}$, R. K. Chadha ${ }^{1}$, C. Singh ${ }^{2}$, and M. Shekar ${ }^{1}$ \\ ${ }^{1}$ National Geophysical Research Institute, Council of Scientific and Industrial Research, Hyderabad 500007, India \\ ${ }^{2}$ Department of Geology and Geophysics, Indian Institute of Technology Kharagpur, West Bengal 721302, India
}

Correspondence to: J. Pavan Kumar (jpawan33@gmail.com)

Received: 19 July 2011 - Revised: 17 January 2012 - Accepted: 18 January 2012 - Published: 30 March 2012

\begin{abstract}
The analysis of the cross-correlation between the seismicity and the daily water level changes in both the Koyna and Warna (India) reservoirs is studied. The time lag between both datasets is calculated and is applied to estimate the hydraulic diffusivity. The range of the hydraulic diffusivity estimated between $0.1 \mathrm{~m}^{2} \mathrm{~s}^{-1}$ and $10 \mathrm{~m}^{2} \mathrm{~s}^{-1}$.
\end{abstract}

\section{Introduction}

Induced seismicity has been observed in a man-made reservoir. Previous researchers (Simpson et al., 1988; Roeloffs, 1988) suggested that the major bursts in seismicity at the reservoir fare of two types, (1) rapid response, i.e., the seismicity immediately follows reservoir impoundment as a direct effect of loading, and (2) delayed response, i.e., seismicity can also occur a long time after impoundment. In this last case, the seismicity can be correlated with the water level or with the rapid increase in the water level. Type 1 seismicity is dominated by the elastic response to the reservoir load, while type 2 is dominated by the pore pressure diffusion process. There are substantial differences in the temporal and spatial characteristics of the response of the crust to these processes and it should be possible to identify the dominant mechanism in some cases, through a comparison of changes in seismicity with the water level in the reservoir (Simpson et al., 1988). The examples for type 1 are at Manic-3 (Leblanc and Anglin, 1978), Monticello (Zoback and Hickman, 1982) and Nurek (Simpson and Negmatullaev, 1981) and type 2 are at Oroville (Toppozada and Morrison, 1982; Gupta and Rastogi, 1976), and Aswan (Kebeasy et al., 1987). The reservoir has often gone through a number of apparently similar annual cycles in water level change without any increased seismicity before the dominant seismicity occurs. Loading is expected to induce seismicity in a tensional stress regime (by adding to the tensional field), whereas unloading will have the same effect in a compressional stress regime. Gupta (1983) suggested that earthquakes of magnitude $M \geq 5$ are expected when the water loading rate exceeds $40 \mathrm{ft}$ per week. On the other hand, Simpson and Negmatullaev (1978) observed in the Nurek Dam area, southern former USSR, an increase in seismic activity with the lowering of water levels in the reservoir.

Continuous reservoir triggered seismicity has been observed since 1963 in the Koyna-Warna region, India after the impoundment of the Koyna reservoir in 1961 and Warna reservoir in 1985. The mechanism of the reservoir induced seismicity in this region was studied by Gupta (2002) and it is due to the diffusion of pore pressure from the reservoirs. The stress memory i.e., in terms of exceeding the previous water level maxima, was found to be the most important factor for the occurrence of high seismicity in the region (Simpson and Negmatullaev, 1981; Gupta, 1983). The reservoir triggered earthquakes have special features like high $b$ value, increase of seismicity with an increase in water level (Gupta et al., 1972a, b). The $b$ value is calculated using GuttenbergRichter relationship.

$\log N=a-b M$

where $N$ is the number of earthquakes, $M$ is magnitude, $a$ and $b$ are constants. " $b$ " is the slope of Guttenberg-Richter magnitude frequency relationship. The $b$ value describes relative size distributions of earthquake. Normally $b$ value is 1.0 , for swarm activity $b$ value will be greater than 1.0 . The recharge of aquifers increase the confined hydrodynamic pressures and flows along the boundary faults which also act as ground water conduits. This, in turn, increases lubrication and decreases the friction along the faults; as a result, 


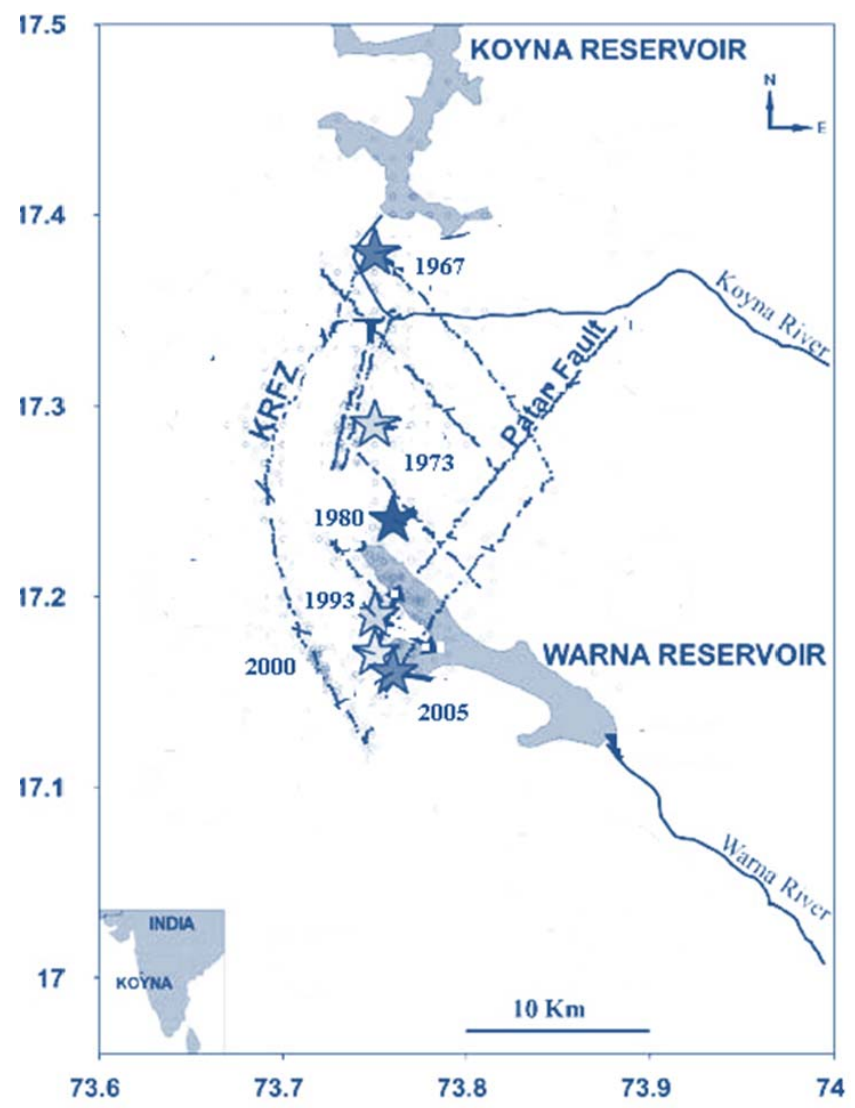

Fig. 1. Location of the Koyna-Warna region. Stars denote the location of the earthquakes of magnitude greater than 5 .

earthquakes which would have occurred later in time are triggered. The empirical correlation between seismicity, rainfall and rivers has been made (Kafri and Shapira, 1990). Such observations by early workers can be interpreted to suggest increases in fluid pressure are transmitted downward into a crystalline permeable upper crust where they trigger earthquakes. The best correlations between the pore pressure diffusion and seismicity are those associated with reservoir induced seismicity. Talwani and Acree (1984/1995) analysed the cases of induced seismicity, which are interpreted as dominated by the pore pressure diffusion and found the hydraulic diffusivity is usually in the range of $0.5 \mathrm{~m}^{2} \mathrm{~s}^{-1}$ to $5.0 \mathrm{~m}^{2} \mathrm{~s}^{-1}$. Recently the vertical diffusivity of the Koyna has been given by Telesca (2010) bases on the analysis of the cross correlation between seismicity and the water level in the Koyna reservoir as $0.2 \mathrm{~m}^{2} \mathrm{~s}^{-1}$. In this work, the crosscorrelation between the water level time series with the earthquake activity in Koyna and Warna reservoirs have been studied and on the bases of the correlation coefficient the range of the hydraulic diffusivity is calculated.

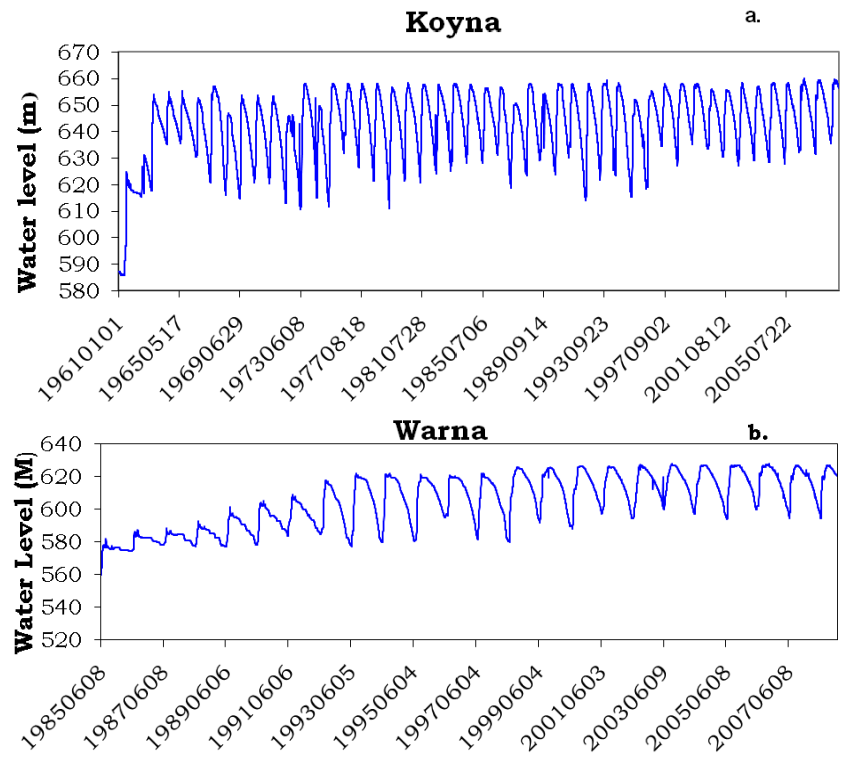

Fig. 2. (a) The Koyna reservoir water level from 1967 to 2008. (b) The Warna reservoir water level from 1985 to 2008.

\section{Data analysis}

Earthquakes in the Koyna-Warna region in India are confined to an epicentre region of about $30 \times 20 \mathrm{~km}^{2}$ (Gupta, 2002). Figure 1 shows the location of the Koyna-Warna region and also the location of the epicentres of the earthquakes of a magnitude greater than $5(M>5)$.

The water levels from the time of impoundment, 1967 in Koyna reservoir and 1985 in Warna reservoir, are shown in Fig. 2. From this Fig. 2, it is clear that the water-level variations in the reservoirs show the annual cycle of loading and unloading. The Koyna reservoir water-level data and the seismicity of this region from 1997 to 2008 have been plotted in Fig. 3.

The correlation between propagation of pore pressure front and depths, and the occurrence of earthquakes of magnitudes exceeding 4.5 , suggests that the pore pressure diffusion is playing a key role in controlling the occurrence of earthquakes associated with Koyna and Warna (Pandey and Chadha, 2003; Talwani, 2000).

The yearly cross correlation between the Koyna reservoir water-level data and the seismicity has been calculated from 1997 to 2008 with a time period of $1 \mathrm{yr}$. The completeness magnitude for the earthquake series is 1.2, i.e., all the events of magnitude greater than or equal to 1.2 are considered in this study. The maximum correlation coefficient and the time lag are computed and are shown in Fig. 4. The cross correlation between the Koyna reservoir water level and the seismicity of the region is shown in Fig. 5 for different years. From Fig. 5, it is clear that the correlation coefficient is between 0.1 and 0.5 . 


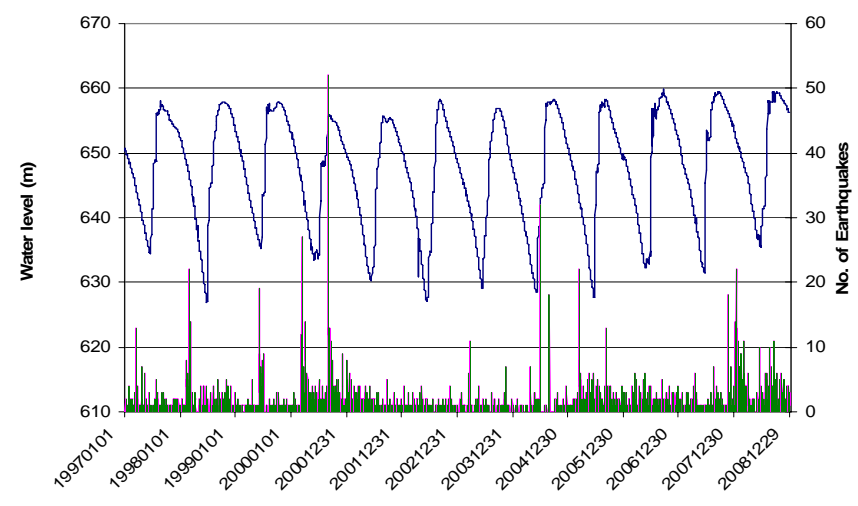

Fig. 3. The Koyna reservoir water levels and the seismicity of the region from 1997 to 2008 .
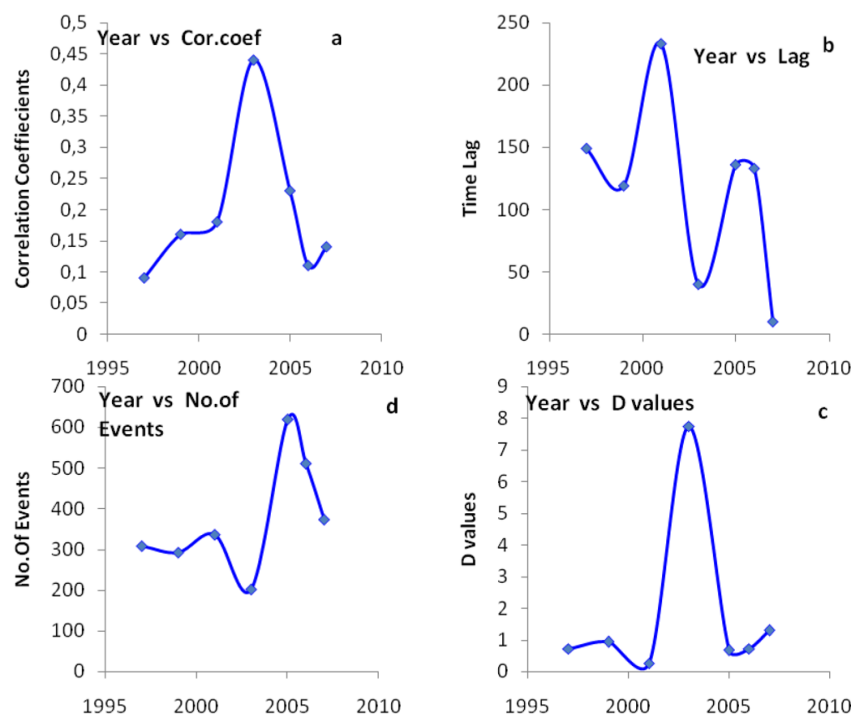

Fig. 4. (a) The maximum correlation coefficient for different years. (b) The time lag for different years. (c) The diffusivity values for different years. (d) The number of events for different years.

To compare the correlation coefficients between water level and seismicity in Konya reservoir and in Warna reservoir, these quantities are also calculated. The results taken from recent arbitrary datasets i.e., from 2000 to 2008 reservoir water level datasets and their correlation coefficients with the seismicity in Konya and in Warna reservoirs are shown in Table 2. From Table 2 it is seen that the correlation coefficient between the seismicity and the water level data in Warna reservoir is either equal or greater than the corresponding correlation coefficient in the Konya reservoir. These results show that the seismicity in the recent year is closer to Warna than Koyna reservoir i.e., Warna reservoir is more dominating than Koyna reservoir. The temporal migration of seismicity from Koyna to Warna in the region is discussed by Rao and Singh (2008) and these results also support the active role of Warna reservoir of recent years.
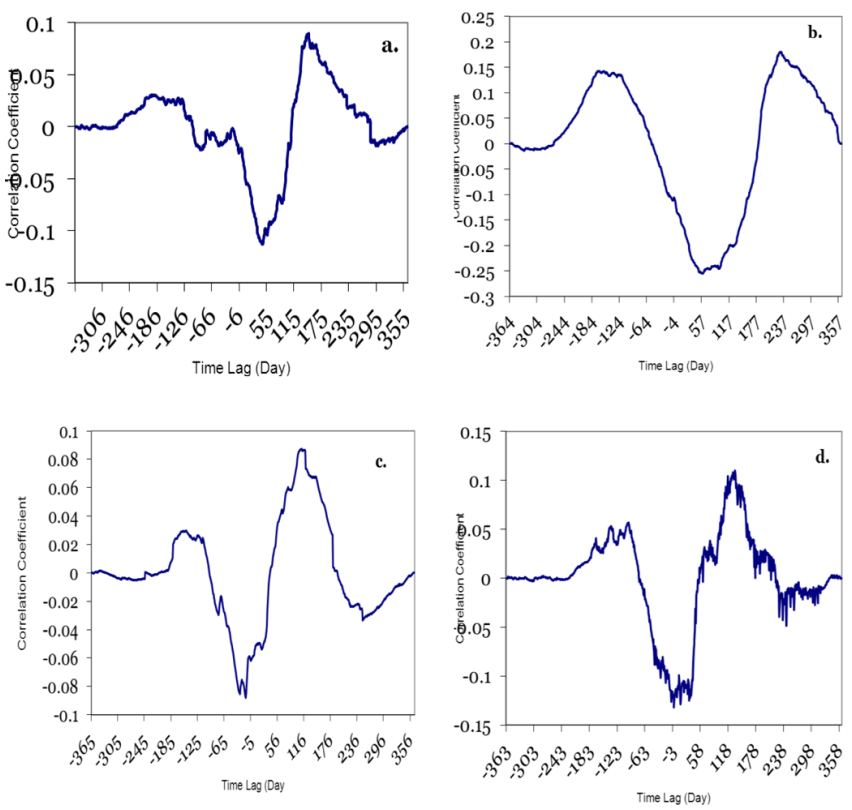

Fig. 5. Cross correlation between Koyna reservoir water level and the seismicity of the region for (a) 1997 (b) 2001 (c) 2004 and (d) 2006.

Table 1. The correlation coefficient, time lag (for Koyna reservoir and Warna reservoir with the seismicity of the region).

\begin{tabular}{rrrrr}
\hline Year & Koyna-coef. & Lag & Warna-coef. & Lag \\
\hline 2000 & 0.14 & 3 & 0.15 & 3 \\
2002 & 0.06 & 212 & 0.06 & 223 \\
2004 & 0.09 & 112 & 0.09 & 110 \\
2006 & 0.11 & 133 & 0.24 & 88 \\
2008 & 0.15 & 13 & 0.25 & 5 \\
\hline
\end{tabular}

Rao and Singh (2008) already discussed the temporal migration of the seismicity; therefore, we analyse the correlation coefficient for both regions separately. The region is divided into two parts by the line at $17.3^{\circ} \mathrm{N}$. Koyna region is above and Warna region below and we calculated the correlation coefficients of Koyna seismicity with the water level of Koyna reservoir and of Warna seismicity with the water level of Warna reservoir. As an example, the correlation coefficient in the year 2008 and the time lag for both cases are calculated to be $0.14,0.20$ and 13 days, 45 days, respectively. The results reveal that the correlation coefficient for the Warna region is higher than the Koyna region, indicating that Warna reservoir is more dominating than Koyna reservoir. In fact migration of the seismicity towards the Warna region occurred.

Figure 6 shows the cross correlation between the Koyna reservoir water level and the seismicity of the region from 2001 to 2004 and from 2005 to 2008, respectively, with a time period of $4 \mathrm{yr}$. The maximum cross-correlation 
Table 2. The correlation coefficient, time lag and hydraulic diffusivity in different time intervals (years).

\begin{tabular}{lrrr}
\hline Year & $\begin{array}{r}\text { Correlation } \\
\text { coefficient }\end{array}$ & $\begin{array}{r}\text { Time } \\
\text { Lag }\end{array}$ & $\begin{array}{r}D \\
\left(\mathrm{~m}^{2} \mathrm{~s}^{-1}\right)\end{array}$ \\
\hline $2001-2004$ & 0.153098 & 235 & 0.26 \\
$2002-2004$ & 0.054345 & 239 & 0.25 \\
$2005-2008$ & 0.092704 & 260 & 0.18 \\
$2006-2007$ & 0.082349 & 387 & 0.09 \\
\hline
\end{tabular}
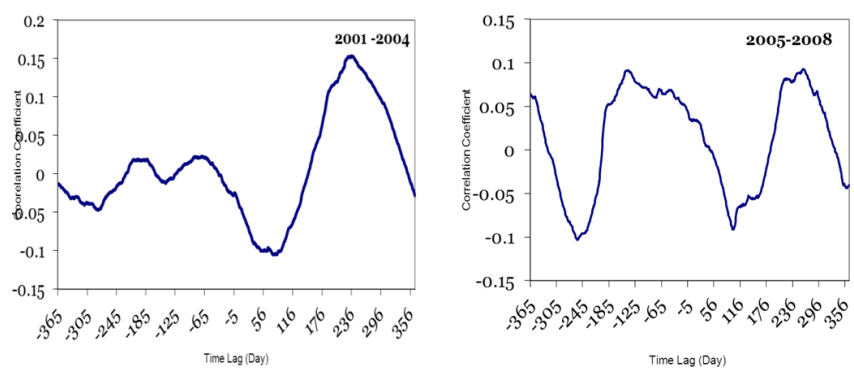

Fig. 6. Cross correlation between the reservoir water level and the seismicity of the region (a) 2001-2004 (b) 2005-2008.

coefficient and the time lag is shown in Table 2. To see the consistency in the correlation coefficient, we also calculated the correlation coefficient and time lag for two more datasets (2006-2007) and (2002-2004), respectively. The maximum cross correlation coefficient and the time lag is shown in Table 2 .

The variation in the hydraulic diffusivity of the region with time is calculated based on the time lag of each year. The diffusivity $D$ obtained by Saar and Manga (2003) with the assumption that the periodic term is zero during the failure time in the Diffusion equation is

$D=\frac{h^{2}}{2 \omega t^{2}}$

where $h$ is the mean depth of the seismic events, $\omega$ is $2 \pi / T$ where $T$ is $1 \mathrm{yr}$ and $t$ is time the lag. The diffusivity $D$ of the Koyna region is given by Telesca (2010) as $0.2 \pm 0.1$ by using the time lag of 223 days obtained from the 2001-2004 datasets of Koyna reservoir water-level data. The present work shows the large variation of the diffusivity value $D$. The numerical results of the diffusivity is calculated for all the time intervals and shown in figure which shows a large range of the diffusivity. For the datasets from 3 to $4 \mathrm{yr}$ the diffusivity value is mostly low and ranges from $0.1 \mathrm{~m}^{2} \mathrm{~s}^{-1}$ to $1.0 \mathrm{~m}^{2} \mathrm{~s}^{-1}$. But for one year sets, the diffusivity values range from $1 \mathrm{~m}^{2} \mathrm{~s}^{-1}$ to $10 \mathrm{~m}^{2} \mathrm{~s}^{-1}$. From most of the cases, we observed that all calculated correlation coefficient values shows $95 \%$ significance. The total from all the results obtained from these studies, it is concluded that the variation in the diffusivity value is very high and the range is from

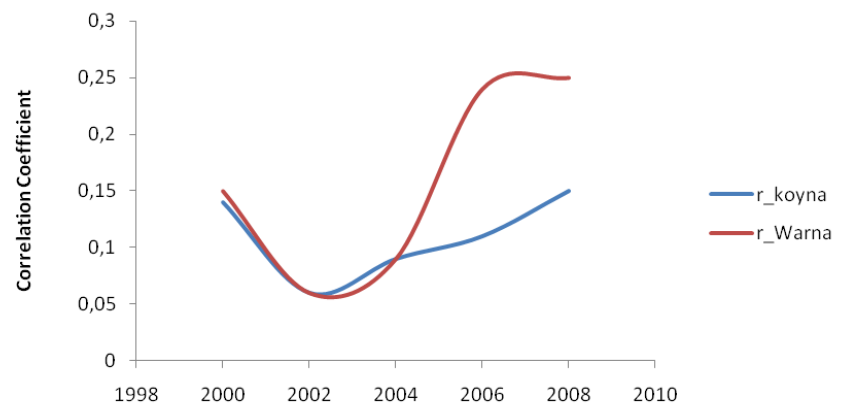

Fig. 7. The maximum correlation coefficients for Koyna and Warna at different time periods.

$0.1-10 \mathrm{~m}^{2} \mathrm{~s}^{-1}$. These values for diffusivity are within the characteristics range $\left(0.1\right.$ to $\left.10 \mathrm{~m}^{2} \mathrm{~s}^{-1}\right)$ for the seismic hydraulic diffusivity found by Talwani and Acree (1985).

\section{Conclusions}

The analysis of the water levels in both reservoirs and the seismicity is shown and the cross correlation between the reservoir water levels and the seismicity suggest different values of time lags. We have observed hydraulic diffusivity $(D)$ as $0.1 \mathrm{~m}^{2} \mathrm{~s}^{-1}$ to $10 \mathrm{~m}^{2} \mathrm{~s}^{-1}$ for the region. The results indicate the active role of Warna reservoir in recent day's seismic activity.

Acknowledgements. The authors are grateful to the Director, National Geophysical Research Institute, for his kind permission to pursue the research.

Edited by: M. E. Contadakis

Reviewed by: two anonymous referees

\section{References}

Gupta, H. K.: Induced seismicity hazard mitigation through water level manipulation at Koyna, India: a suggestion, Bull. Seismol. Soc. Am., 73, 679-682, 1983.

Gupta, H. K.: A review of recent studies of triggered earthquakes by artificial water reservoirs with special emphasis on earthquakes in Koyna, India. Earth Sci. Rev., 58, 279-310, 2002.

Gupta, H. K. and Rastogi, B. K.: Dams and Earthquakes, Elsevier, Amsterdam, 229 pp., 1976.

Gupta, H. K., Rastogi, B. K., and Narain, H.: Common features of the reservoir-associated seismic activities, Bull. Seismol. Soc. Am., 62, 481-492, 1972a.

Gupta, H. K., Rastogi, B. K., and Narain, H.: Some discriminatory characteristics of earthquakes near the Kariba, Kremasta, and Koyna artificial lakes, Bull. Seismol. Soc. Am., 62, 493-507, 1972b.

Kafri, U. and Shapira, A.: A correlation between earthquake occurrence, rainfall and water level in Lake Kinnereth, Israel, Phys. Earth Planet. Int., 62, 277—283, 1990. 
Kebeasy, R. M., Maamoun, M., Ibrahim, E., Megahed, A., Simpson, D. W., and Leith, W. S.: Earthquake studies at Aswan reservoir, J. Geodynam., 7, 173-193, 1987.

Leblanc, G. and Anglin, F.: Induced seismicity at the Manic 3 Reservoir, Quebec, Bull. Seismol. Soc. Am., 68, 1469-1485, 1978.

Pandey, A. P. and Chadha, R. K.: Surface loading and triggered earthquakes in the Koyna-Warna region, western India, Phys. Earth Planet. Int., 139, 207-223, 2003.

Rao, B. R. and Singh, C.: Temporal migration of earthquakes in Koyna-Warna (India) region by pore-fluid diffusion, J. Seismol., 12, 547-556, 2008.

Roeloffs, E. A.: Fault stability changes induced beneath a reservoir with cyclic variations in water level, J. Geophys. Res., 83, 21072124, 1988.

Saar, M. O. and Manga, M.: Seismicity induced by seasonal groundwater recharge at Mt. Hood, Oregon, Earth Planet. Sci. Lett., 214, 605-618, 2003.

Simpson, D. W.: Triggered earthquakes, Ann. Rev. Earth Planet. Sci., 14, 21-42, 1986.

Simpson, D. W. and Negmatullaev, S. Kh.: Induced seismicity studies in Soviet central Asia, Earthq. Inf. Bull., 10, 208-213, 1978.
Simpson, D. W. and Negmatullaev, S. K.: Induced seismicity at Nurek Reservoir, Tadjikistan, USSR, Bull. Seismol. Soc. Am., 71, 1561-1586, 1981.

Simpson, D. W., Leith, W. S., and Scholz, C. H.: Two types of reservoir induced seismicity, Bull. Seism. Soc. Am., 78, 20252040, 1988.

Talwani, P.: Seismogenic properties of the crust inferred from recent studies of reservoir-induced seismicity - Application to Koyna, Curr. Sci. India, 79, 1327-1333, 2000.

Talwani, P. and Acree, S.: Pore pressure and the mechanism of reservoir induced seismicity, Pure Appl. Geophys., 122, 947965, 1984/1985.

Telesca, L.: Analysis of the cross correlation between seismicity and water level in the Koyna area of India, Bull. Seism. Soc. Am., 100, 2317-2321, 2010.

Toppozada, T. R. and Morrison, P. W.: Earthquakes and lake levels at Oroville, California, Calif. Geol., 35, 115-118, 1982.

Zoback, M. D. and Hickman, S.: In situ study of the physical mechanisms controlling induced seismicity at Monticello reservoir, South Carolina, J. Geophys. Res., 87, 6959-6974, 1982. 